\title{
Germinação de Salvia splendens L. submetida à salinidade ${ }^{(1)}$
}

\author{
DEREK BRITO CHAIM JARDIM ROSA(2); JACKELINE SCHULTZ SOARES(4); \\ LEANDRO BASSI MORENO(2); GUILHERME SILVA MICHELS(2); CAMILA SOARES ROSA LEMES(2); \\ SILVANA DE PAULA QUINTÃO SCALON(3); YARA BRITO CHAIM JARDIM ROSA(3);
}

\begin{abstract}
RESUMO
A salinidade é fator limitante para que ocorra germinação na maioria das espécies sendo necessários estudos que avaliem a interação entre plantas e o ambiente salino ao qual estão associadas. O presente estudo consistiu em avaliar a germinação e características de vigor em Salvia splendens submetidas à salinidade. As sementes foram expostas a diferentes potenciais osmóticos, simulando condições de estresse salino, provocado por $\mathrm{NaCl}, \mathrm{CaCl} 2$ e $\mathrm{KCl}$ nos potenciais de $0 ;-0,4 ;-0,8 ;-1,2$; -1,6 e -2,0 MPa. De modo geral, pode-se observar que o $\mathrm{CaCl} 2$ resultou em melhores resultados para todas as variáveis analisadas, provavelmente ligado ao efeito positivo do $\mathrm{Ca} 2+$ no metabolismo celular, permitindo germinação $60,81 \%$ no potencial osmótico de $-1,35 \mathrm{MPa}$.
\end{abstract}

Palavras-chave: Lamiaceae, potencial osmótico, cálcio.

\begin{abstract}
Germination of Salvia splendens L. subjected to salinity

ABSTRACT: The salinity is a limiting factor for germination to occur in most species being necessary studies that assess the interaction between plants and saline environment to which they are being associated. The present study had as aim to evaluate the germination and characteristics of vigor in Salvia splendens subjected to salinity. The seeds were exposed to different osmotic potentials, simulating salt stress caused by $\mathrm{NaCl}, \mathrm{KCl}$ and $\mathrm{CaCl} 2$ at potentials of $0,-0.4,-0.8,-1.2,-1.6$ and $-2.0 \mathrm{MPa}$. In general, $\mathrm{CaCl} 2$ led to the best results for all variables, probably connected to the positive effect of $\mathrm{Ca} 2+$ in cell metabolism, allowing germination of $60.81 \%$ in the osmotic potential of $-1.35 \mathrm{MPa}$.
\end{abstract}

Keywords: Lamiaceae, osmotic potential, calcium.

\section{INTRODUÇÃO}

A sálvia-anã-de-jardim, ou sálvia-brilhante, (Salvia splendens L. - Lamiaceae) é uma planta anual, podendo também comportar-se como bianual, atingindo até $80 \mathrm{~cm}$ de altura. Apresenta intensa floração durante o ano todo, com flores de coloração vermelha. Nativa do Brasil, é amplamente utilizada em jardins no mundo todo, especialmente na Europa (MENEZES et al., 2004).

Sua principal forma de propagação é semífera (LORENZI e SOUZA, 2001), no entanto, para a obtenção de uma alta taxa de plântulas normais e vigorosas é necessária a adequação de vários fatores que interferem no processo germinativo, tais como a quantidade e qualidade da luz, a umidade, a temperatura, o aporte nutricional do substrato e a ausência de elementos tóxicos (NAKAGAWA, 1999).

Outro fator limitante tanto para a germinação quanto para o crescimento inicial de plântulas é a salinidade do substrato. Segundo Tobe et al. (2000) a inibição do crescimento devido à salinidade se deve ao efeito osmótico e também ao efeito tóxico, este último resultante da concentração de íons no protoplasma. Hu e Schmidhalter (2005) salientam, ainda, que estes efeitos se devem ao desequilíbrio na absorção de nutrientes minerais, bem como a fitotoxicidade pela acumulação excessiva de íons $\mathrm{Na}^{+}$e $\mathrm{Cl}^{-}$nos tecidos.

Vários são os trabalhos que tratam do estresse salino em espécies ornamentais - Rosa L. (NIU E RODRIGUEZ, 2008); Asteriscus maritimus (RODRÍGUEZ et al., 2005); Calceolaria hybrida, Calendula officinalis e Petunia hybrida (FORNES et al., 2007); Heliconiaceae (BARROS et al., 2010) - porém poucos são os referentes à sálvia (IBRAHIM et al., 1991; KANG E VAN IERSEL, 2004). Em vista disso, objetivou-se avaliar o efeito de diferentes potenciais osmóticos sobre a germinação de sementes e o vigor de plântulas de S. splendens.

\section{MATERIAL E MÉTODOS}

O trabalho foi realizado em laboratório da Faculdade de Ciências Agrárias - FCA, na Universidade Federal da Grande Dourados - UFGD. Foram utilizadas como material de estudo, sementes de $S$. splendens, com grau de umidade de 5,77\%, previamente desinfestadas em solução de hipoclorito de sódio P.A. a 5\% por 10 minutos e submetidas à germinação em diferentes potenciais osmóticos, simulando condições de estresse salino, provocado por $\mathrm{NaCl}, \mathrm{CaCl}_{2}$ ou $\mathrm{KCl}$ nos potenciais de

\footnotetext{
(1) Trabalho recebido para publicação em 14/01/2014 e aprovado em 17/11/2014

(2) Universidade Federal da Grande Dourados (UFGD), Faculdade de Ciências Agrárias (FCA), Rodovia Dourados à Itahum, km 12, Caixa Postal 533, 79804-970 - Dourados - MS. *Autor correspondente: derekrosa@gmail.com
} 
$0 ;-0,4 ;-0,8 ;-1,2 ;-1,6$ e -2,0 MPa, estabelecidos pela equação de Van’t Hoff (Taiz e Zeiger, 2004).

$\mathrm{O}$ teste de germinação consistiu em alocar 50 sementes em caixa tipo gerbox, sobre duas folhas de papel Germitest ${ }^{\circledR}$, previamente umedecidas com solução salina conforme as RAS (BRASIL, 2009). Para cada condição salina foram utilizadas quatro repetições de 50 sementes cada. Em seguida, os gerbox foram mantidos em câmara B.O.D. à temperatura e luminosidade constantes $\left(25^{\circ} \mathrm{C}\right.$; $525 \mu \mathrm{mol} \mathrm{m} \mathrm{m}^{-2} \mathrm{~s}^{-1}$.

Sete dias após a implantação do experimento foi contabilizado o número de plantas germinadas, para a avaliação do vigor. Decorridos 21 dias, foram avaliados o número de plântulas normais, anormais e de sementes mortas. Para as duas avaliações, considerou-se como germinadas as sementes que emitiram radícula com $2 \mathrm{~mm}$ de comprimento (BRASIL, 2009; NAKAGAWA, 1999). O mesmo padrão foi adotado para avaliação do índice de velocidade de germinação (IVG). Foram consideradas plântulas normais as que apresentaram todas as suas estruturas essenciais: radícula, hipocótilo e cotilédone (NAKAGAWA, 1999).

Para avaliação do crescimento das plântulas, quatro repetições, com 15 sementes cada, foram organizadas em rolos de papel Germitest ${ }^{\circledR}$, conforme RAS (BRASIL, 2009); previamente umedecidas com a solução salina a ser testada. Em seguida, os rolos foram envoltos em sacos de polietileno e mantidos em câmara B.O.D. à temperatura constante de $25{ }^{\circ} \mathrm{C}$. Transcorridos 21 dias, foram selecionadas, aleatoriamente, 10 plântulas de cada repetição e estas avaliadas quanto ao comprimento e, posteriormente, à massa seca (NAKAGAWA, 1999).

O delineamento experimental utilizado foi inteiramente casualizado e os tratamentos foram arranjados em esquema fatorial 3 × 6 (3 sais e 6 potenciais osmóticos) com quatro repetições. Para análise dos resultados foi utilizado o programa estatístico SISVAR 5.3 (FERREIRA, 2010) e os fatores, quando significativos, foram comparados por teste de médias (Tukey 5\%) ou por regressão.

\section{RESULTADOS E DISCUSSÃO}

Efeito conjunto $(p<0,01)$ dos sais estudados e dos potenciais osmóticos foi observado sobre a maioria das variáveis analisadas, excetuando-se $(\mathrm{p}>0,05)$ a primeira contagem e o comprimento de plântulas. Efeitos isolados do potencial osmótico e dos sais foram registrados $(p<0,05)$ sobre a primeira contagem. O comprimento das plântulas não foi influenciado pelo potencial osmótico, e nem pelos sais estudados $(\mathrm{p}>0,05)$, apresentando valor médio de $0,11 \mathrm{~cm}$.

Os maiores valores de germinação foram obtidos com o uso de $\mathrm{CaCl}_{2}(81,49 \%)$ no potencial osmótico de $-1,5 \mathrm{MPa}$, seguido pelo $\mathrm{NaCl}(70,20 \%)$ a $-0,85 \mathrm{MPa}$ e $\mathrm{KCl}(70,16 \%)$ que não diferiu estatisticamente em nenhum dos potenciais osmóticos estudados (Figura 1).

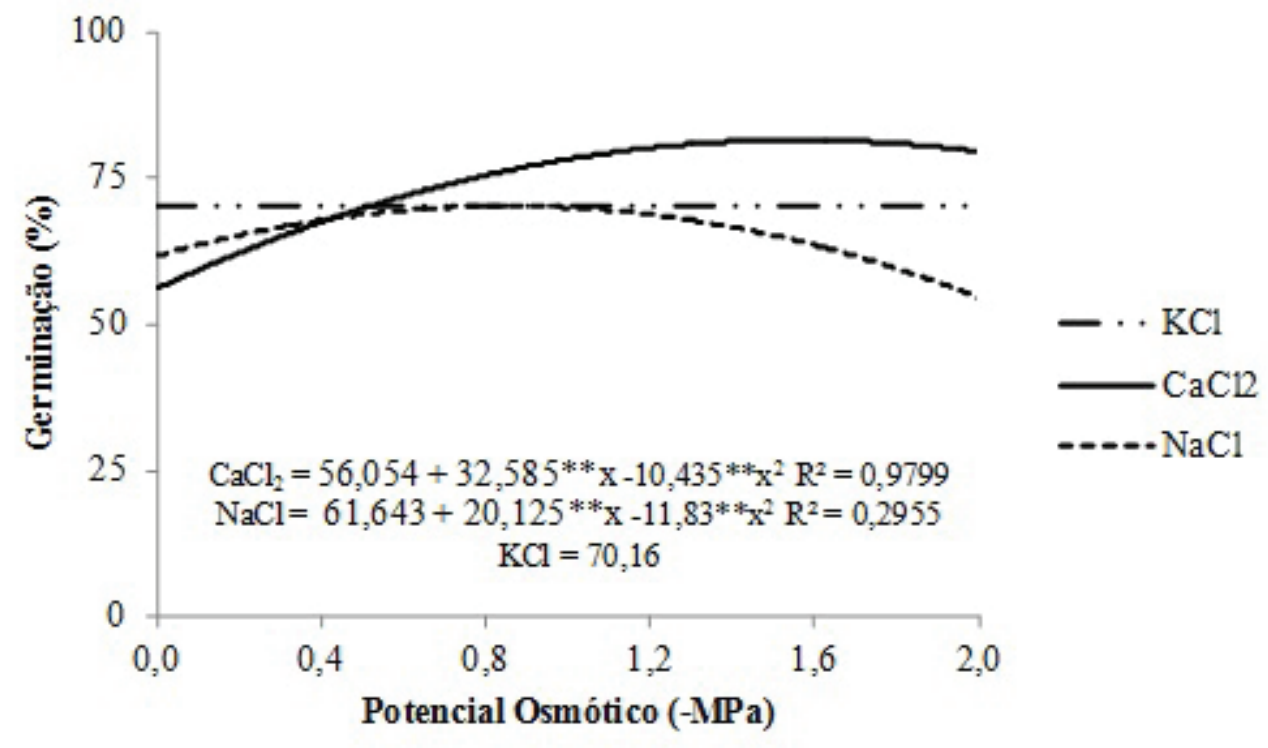

Figura 1. Efeito dos sais e do potencial osmótico sobre a porcentagem de germinação de Salvia splendens. Dourados, UFGD, 2013

Figure 1. Effect of salts and osmotic potential on the germination of Salvia splendens. Dourados, UFGD, 2013 
O mesmo padrão de resposta foi encontrado no índice de velocidade de germinação (IVG) (Figura 2), sendo os maiores resultados observados com a utilização do $\mathrm{CaCl}_{2}(60,81)$ no potencial osmótico de-1,35 MPa, seguido pelo $\mathrm{NaCl}(58,21)$ a $-0,70 \mathrm{MPa}$ e pelo $\mathrm{KCl}(57,78)$, que não diferiu estatisticamente em nenhum dos potenciais osmóticos avaliados.

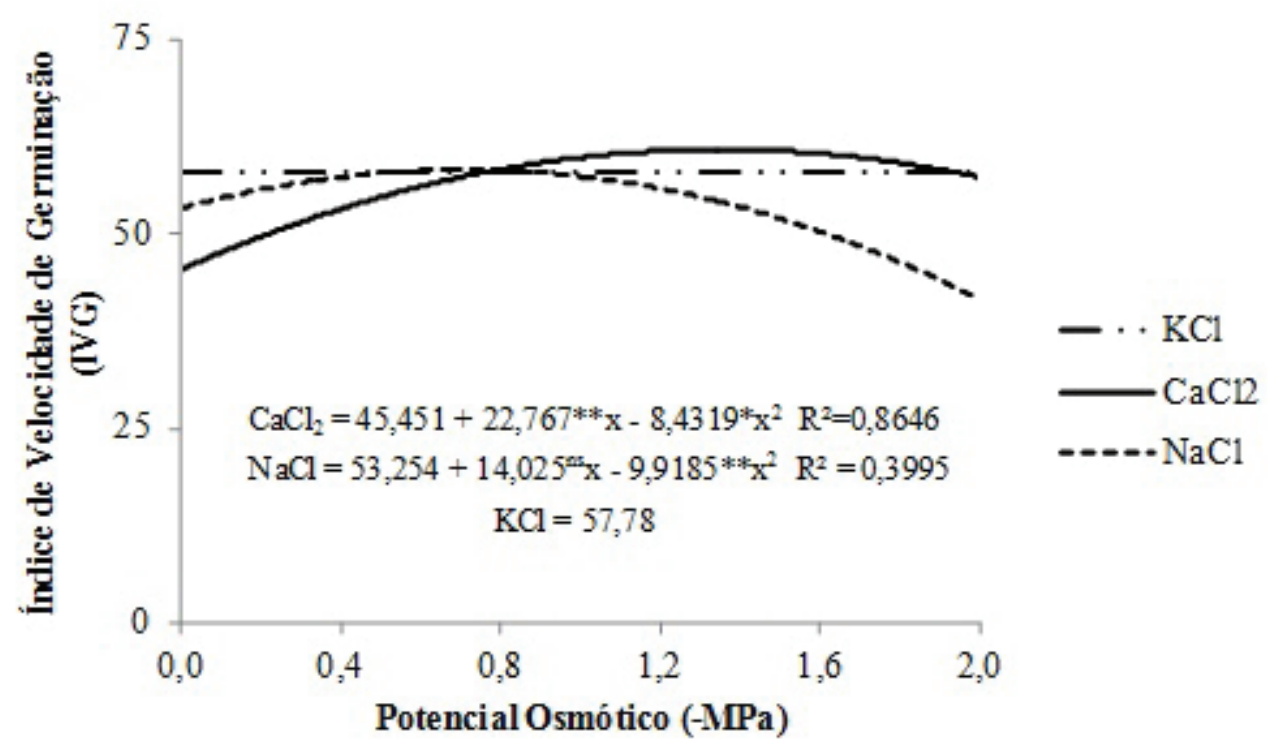

Figura 2. Efeito dos sais e do potencial osmótico sobre o índice de velocidade de germinação de Salvia splendens. Dourados, UFGD, 2013

Figure 2. Effect of salts and osmotic potential on the germination speed index (IVG) of Salvia splendens. Dourados, UFGD, 2013

Os resultados observados podem estar relacionados com as funções do $\mathrm{Ca}^{+2}$, que além de ser essencial na manutenção da integridade da membrana plasmática, contribui para a diminuição do extravazamento de $\mathrm{K}^{+}$, o qual é responsável pela síntese de proteínas, amido e ativação de muitas enzimas no processo germinativo (CATALAN et al., 1994; FRANCO et al., 1999), possibilitando a mobilização de reservas e, consequentemente, a melhor adaptação quando comparado às demais situações estressoras.

De acordo com Braccini et al. (1996), a diminuição acentuada da germinação das sementes de soja em maiores concentrações de $\mathrm{NaCl}$ deve-se à menor quantidade de água absorvida pelas sementes em função da redução do potencial osmótico das soluções, afetando diretamente a mobilização das reservas. Essa relação também foi verificada por Smith et al. (1989) com sementes de sorgo e milheto que tiveram sua germinação uniformemente diminuída com a redução do potencial osmótico, sendo que no potencial de -1,2 MPa houve diminuição acentuada da germinação, assim como observado com sálvia, neste trabalho, para o mesmo sal.

A inibição da mobilização das reservas, segundo Prisco et al. (1981), pode também ser atribuída aos efeitos dos sais na síntese "de novo" das purinas e na atividade das enzimas responsáveis pela hidrólise e translocação dos produtos hidrolizados dos tecidos de reserva para o eixo embrionário, afetando deste modo, o processo germinativo.

O maior peso seco de plântulas $(6,10 \mathrm{~g})$ foi registrado com a utilização de $\mathrm{CaCl}_{2}$ no potencial osmótico de $-2,0$ $\mathrm{MPa}$. Para este mesmo sal o menor valor $(3,83 \mathrm{~g})$ foi observado no potencial de -0,79 MPa, sendo estatisticamente semelhante ao valor máximo observado com a utilização de $\mathrm{KCl}(3,85 \mathrm{~g})$ e ao valor médio registrado para $\mathrm{NaCl}(3,72$ g) (Figura 3). 


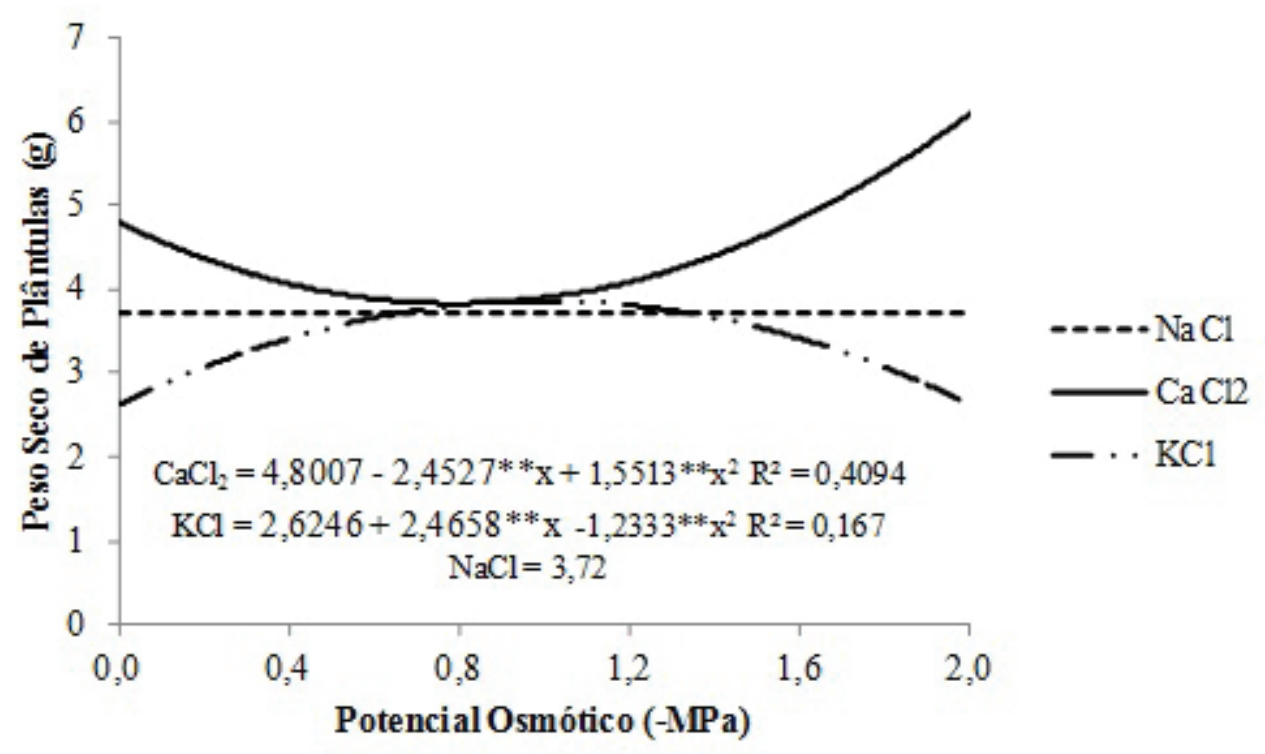

Figura 3. Efeito dos sais e do potencial osmótico sobre o peso seco de plântulas de Salvia splendens. Dourados, UFGD, 2013

Figure 3. Effect of salts and osmotic potential on the dry weight of seedlings of Salvia splendens. Dourados, UFGD, 2013

Uma provável explicação para esses resultados seria o fato do $\mathrm{Ca}^{+2}$ estar relacionado a processos fisiológicos que afetam o transporte de açúcares e a síntese da parede celular, destacando-se como um fator importante para maximizar o processo de lignificação das células vegetais (CAKMAK e ROHMHELD, 1997), e com isso, garantir incrementos em massa seca. Lacerda et al. (2004) trabalhando com plântulas estressadas de sorgo, observaram que o $\mathrm{Ca}^{2+}$ foi fundamental para a manutenção de teores mais adequados de íons nos tecidos vegetais, reduzido parcialmente os efeitos da salinidade sobre a produção de massa seca na parte aérea.

A menor porcentagem de sementes mortas $(24,93 \%)$ foi registrada com o uso de $\mathrm{CaCl}_{2}$ no potencial de -1,3 MPa. Para o $\mathrm{NaCl}$, valor mínimo (36,81\%) foi observado no potencial de $-0,75 \mathrm{MPa}$ e, para o $\mathrm{KCl}$, não houve diferença estatística entre os potencias estudados, sendo registrado um valor médio de $42,25 \%$ de sementes mortas (Figura 4). Ressalta-se que mesmo no maior potencial de $\mathrm{CaCl}_{2}$ o número de sementes mortas ainda se manteve menor do que em todos os potenciais dos demais sais.

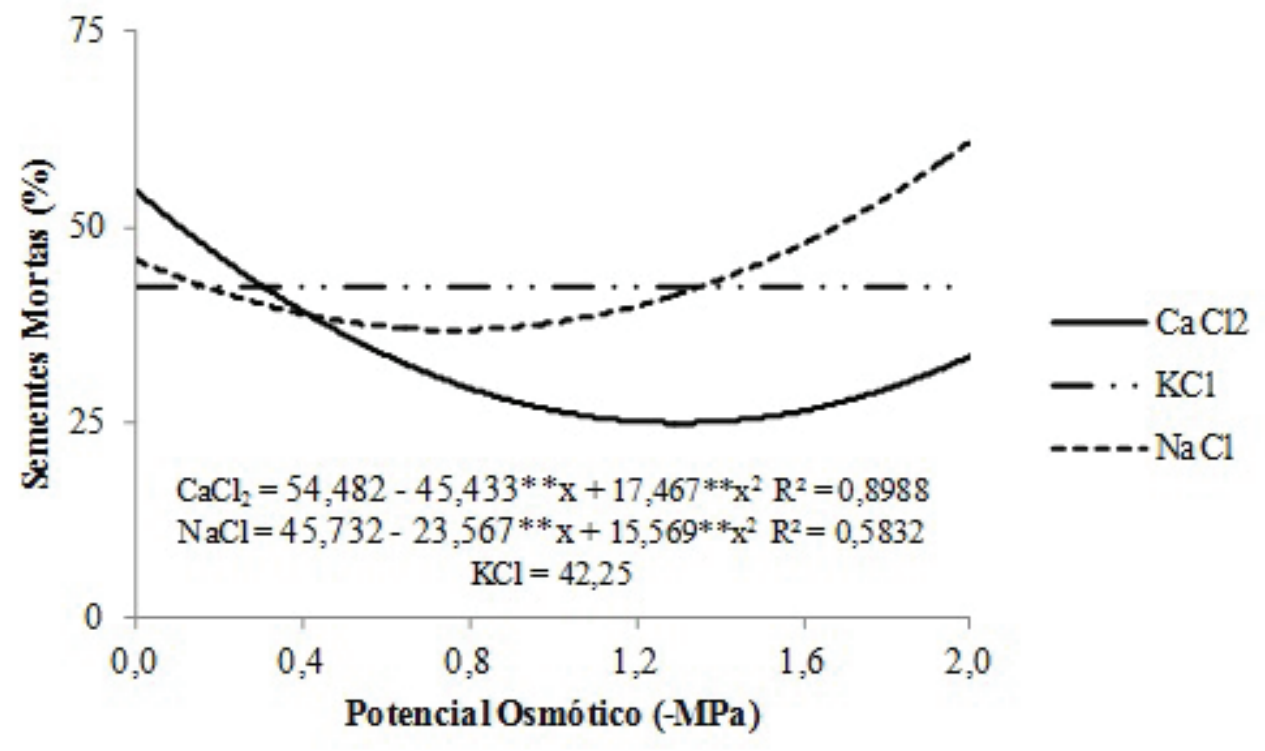

Figura 4. Efeito dos sais e do potencial osmótico sobre a porcentagem de sementes mortas de Salvia splendens. Dourados, UFGD, 2013

Figure 4. Effect of salts and osmotic potential on percentage of dead seeds of Salvia splendens. Dourados, UFGD, 2013 
As maiores porcentagens de plântulas anormais (Figura 5), de modo geral, foram observadas com o uso dos sais de $\mathrm{KCl}$ e $\mathrm{NaCl}$, observando-se valores médios de $36,33 \%$ e $31,91 \%$ respectivamente. Com o $\mathrm{CaCl}_{2}$ foi observada a menor porcentagem de plântulas anormais $(18,41 \%)$ no potencial osmótico de $-0,28 \mathrm{MPa}$.

O estresse salino leva à diminuição do processo de absorção de água e ao aumento da entrada dos íons, provocando toxicidade às sementes (TOBE et al., 2000). $\mathrm{O} \mathrm{Na}^{+}$e o $\mathrm{Cl}^{\text {, }}$, são apontados como uma das principais causas da redução da velocidade dos processos fisiológicos e bioquímicos (TOBE et al., 2000; FLOWERS, 2004), podendo ser a causa, mesmo nas condições de baixos potenciais osmóticos, dos elevados índices de sementes mortas e plântulas anormais, na presença de $\mathrm{NaCl}$ e $\mathrm{KCl}$.

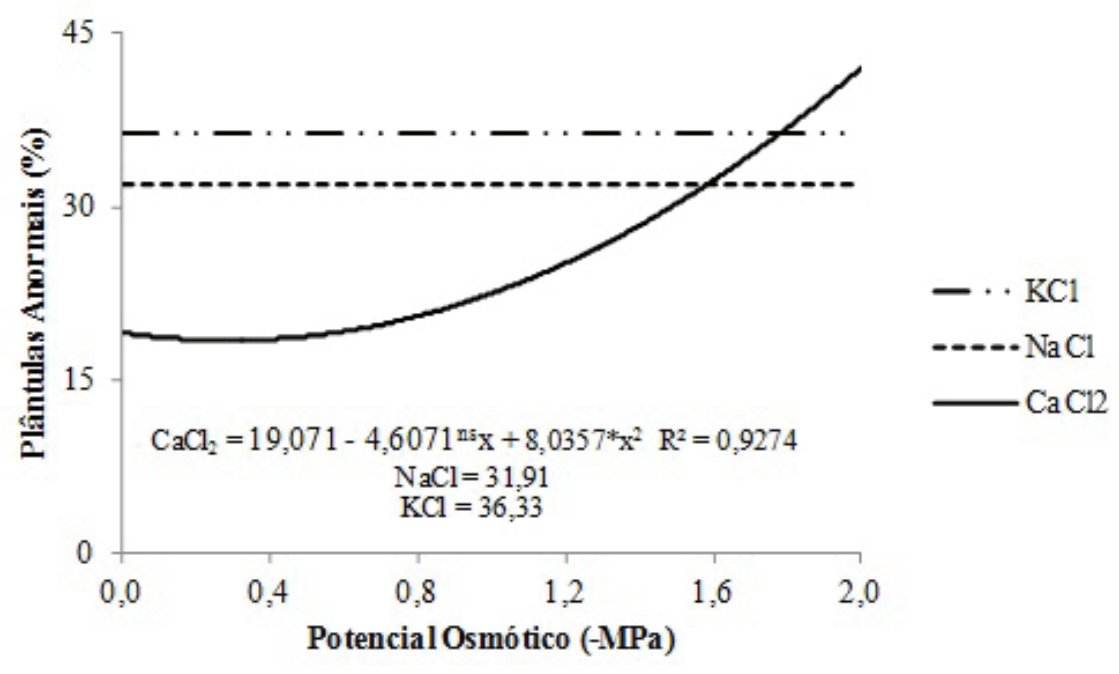

Figura 5. Efeito dos sais e do potencial osmótico sobre a porcentagem de plântulas anormais de Salvia splendens. Dourados, UFGD, 2013

Figure 5. Effect of salts and osmotic potential on the percentage of abnormal seedlings of Salvia splendens. Dourados, UFGD, 2013

O valor máximo de plântulas normais (50,99\%) foi obtido com o uso de $\mathrm{CaCl}_{2}$ no potencial osmótico de $-0,98$ Mpa. Para o $\mathrm{NaCl}$, o valor máximo registrado $(32,56 \%)$ foi alcançado a $-0,87 \mathrm{MPa}$ e, para o $\mathrm{KCl}$, os potenciais osmóticos estudados não apresentaram influência significativa para essa variável, observando-se o valor médio de $21,41 \%$ de plântulas normais (Figura 6).

Mesmo na presença de $\mathrm{Cl}^{-}$, a aplicação de $\mathrm{CaCl}_{2}$, permitiu a elevação da concentração de $\mathrm{Ca}^{2+}$ no ambiente. Este elemento é apontado como um agente mitigador dos efeitos negativos da salinidade sobre o crescimento das plantas, podendo explicar as maiores porcentagens de plântulas normais. Considera-se que o $\mathrm{Ca}^{2+}$ também promove o acúmulo de solutos orgânicos, como a prolina e a glicinabetaina (LÄUCHLI et al., 1994; COLMER et al., 1996; GIRIJA et al., 2002 apud LACERDA et al., 2004), os quais possibilitariam o estabelecimento de um equilíbrio osmótico no citoplasma mais compatível com o metabolismo celular, favorecendo o crescimento das plântulas sob condições de estresse salino. 


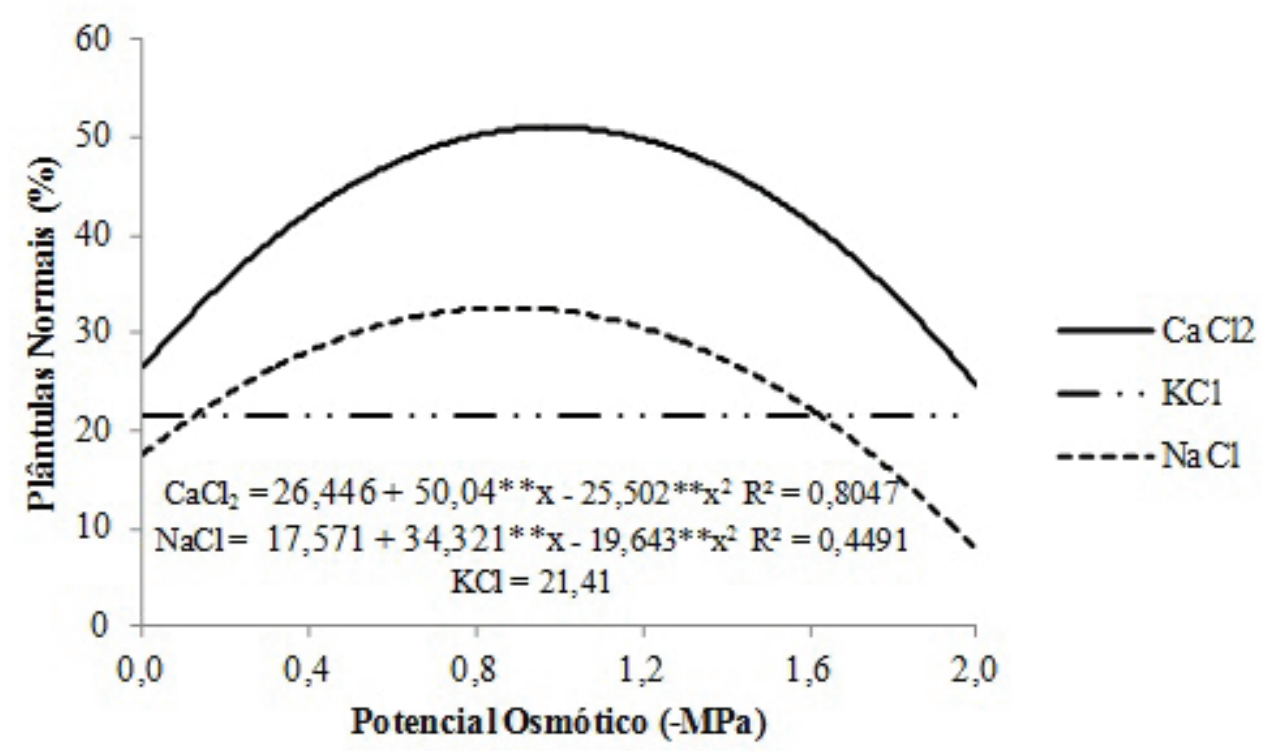

Figura 6. Efeito dos sais e do potencial osmótico sobre a porcentagem de plântulas normais de Salvia splendens. Dourados, UFGD, 2013

Figure 6. Effect of salts and osmotic potential on the percentage of normal seedlings of Salvia splendens. Dourados, UFGD, 2013

\section{CONCLUSÕES}

As sementes de $S$. splendens apresentam um limite de tolerância aos sais $\mathrm{KCl}$ e $\mathrm{NaCl}$ até aproximadamente $-0,85$ $\mathrm{MPa}$. Abaixo desse potencial ocorre a inibição tanto da viabilidade quanto do vigor das sementes dessa espécie.

A aplicação de $\mathrm{CaCl}_{2}$ no potencial osmótico de $-1,2$ $\mathrm{MPa}$ propiciou maior número de sementes germinadas e plântulas normais de $S$. splendens.

\section{REFERÊNCIAS}

BARROS, H.M.M.; GHEY, H.R.; LOGES, V.; SANTOS, M.S.; SOARES, F.A.L. Influência da salinidade da água no crescimento de seis genótipos de Helicônias. Revista Brasileira de Horticultura Ornamental, Campinas, v.16, n.2, p.139-145, 2010.

BRACCINI, A.L.; RUIZ, H.A.; BRACCINI, M.C.L.; REIS, M.S. Germinação e vigor de sementes de soja sob estresse hídrico induzido por soluções de cloreto de sódio, manitol e polietileno glicol. Revista Brasileira de Sementes, Brasília, v.18, n.1, p.10-16, 1996.

BRASIL. Ministério da Agricultura. Regras para análises de sementes. Brasília: Mapa/ASC, 2009. 399p.

CAKMAK, I.; ROHMHELD, V. Boron deficiency-induced impairments of cellular functions in plants. Plant and Soil, The Hague, v.193, n.1/2, p.71-83, 1997
CATALAN, L.; BALZARINI, Z.; ALESNIK, E.; SERENO, R.; KARLIN, U. Effects of salinity on germination and seedling growth of Prosopis flexuosa (D.C.). Forest Ecology and Management, v.63, p.347-357, 1994.

FERREIRA, D.F. Programa de análises estatísticas (Statistical Analysis Software) e planejamento de Experimentos - SISVAR 5.3. Lavras: UFLA, 2010.

FLOWERS, T.J. Improving crop salt tolerance. Journal of Experimental Botany, v.55, n.396, p.307-319, 2004.

FRANCO, O.L.; ENEAS FILHO, J.; PRISCO, J.T.; GOMES FILHO, E. Effects of $\mathrm{CaCl}_{2}$ on the growth and osmoregulator accumulation in $\mathrm{NaCl}$ stressed cowpea seedlings. Revista Brasileira de Fisiologia Vegetal, v.11, n.3, p.145-151, 1999.

FORNES F.; BELDA R.M.; CARRIÓN C.; NOGUERA V.; GARCÍA-AGUSTÍN P.; ABAD M. Pre-conditioning ornamental plants to drought by means of saline water irrigation as related to salinity tolerance. Scientia Horticulturae, v.113, p.52-59, 2007.

HU, Y.; SCHMIDHALTER, U. Drought and salinity: A comparison of their effects on mineral nutrition of plants. Journal of Plant Nutrition and Soil Science, v.168, n.4, p.541-549, 2005. 
IBRAHIM, K.M.; COLLINS, J.C.; COLLIN, H.A. Effects of salinity on growth and ionic composition of Coleus blumei and Salvia splendens. Journal of Horticulture Science, v.66, p.215-222, 1991.

KANG, J.G. e M.W. van IERSEL. Nutrient solution concentration affects shoot: root ratio, leaf area ratio, and growth of subirrigated salvia (Salvia splendens). HortScience, v.39, p.49-54, 2004.

LACERDA, C.F. et al. Influência do cálcio sobre o crescimento e solutos em plântulas de sorgo estressadas com cloreto de sódio. Revista Brasileira de Ciência do Solo, v.28, n.2, 2004.

LORENZI, H.; SOUZA, H.M. Plantas Ornamentais no Brasil - arbustivas, herbáceas e trepadeiras. 3a. edição. Nova Odessa - SP: Instituto Plantarum. 2001, 1120p.

MENEZES, N.L; FRANZIN, S.M; ROVERSI, T; NUNES, E.P. Germinação de sementes de Salvia splendens Sellow em diferentes temperaturas e qualidades de luz. Revista Brasileira de Sementes, v.26, n.1, p.32-37, 2004.

NAKAGAWA, J. Testes de vigor baseados nos desempenhos das plântulas. In: KRZYZANOWSKI, F.C.; VIEIRA, R.D.; FRANÇA NETO, J.B. (Ed.). Vigor de sementes: conceitos e testes. Londrina: ABRATES, 1999.
NIU, G.; RODRIGUEZ, D.S. Responses of growth and ion uptake of four rose rootstocks to chloride- or sulfatedominated salinity. Journal of the American Society for Horticultural Science, v.133, p.663-669, 2008.

PRISCO, J.T.; ENEAS FILHO, J.; GOMES FILHO, E. Effect of $\mathrm{NaCl}$ salinity on cotyledon starch mobilization during germination of Vigna unguiculata (L.) Walp seeds. Revista Brasileira de Botânica, v.4, p.63-71, 1981.

RODRÍGUEZ, P.; TORRECILLAS, A.; MORALES, M.A.; ORTUÑO, M.F.; SÁNCHEZ-BLANCO, M.J. Effects of $\mathrm{NaCl}$ salinity and water stress on growth and water relations of Asteriscus maritimus plants. Environmental and Experimental Botany, v.53, p.113-123, 2005.

SMITH, R.L.; HOVELAND, C.S.; HANA, W.W. Water stress and temperature in relation to seed germination of pearl millet and sorghum. Agronomy Journal, v.81, n.2, p.303-305, 1989.

TAIZ, L; ZEIGER, E. Fisiologia Vegetal. 3. ed. Porto Alegre: Artmed, 2004. 719p.

TOBE, K.; LI, X.; OMASA, K. Seed germination and radicle growth of a halophyte, Kalidium caspicum (Chenopodiaceae). Annals of Botany, v.85, p.391-396, 2000 . 
